Discussion Paper No. 579

\title{
DOES AGENCY COST MODEL EXPLAIN BUSINESS FLUCTUATIONS IN JAPAN?: AN EMPIRICAL ATTEMPT TO ESTIMATE AGENCY COST BY FIRM SIZE
}

\author{
Kazuo Ogawa \\ and \\ Hirokuni Uchiyama
}

April 2003

The Institute of Social and Economic Research Osaka University

6-1 Mihogaoka, Ibaraki, Osaka 567-0047, Japan 
Does Agency Cost Model Explain Business Fluctuations in Japan? : An Empirical Attempt to Estimate Agency Cost by Firm Size*

\author{
Kazuo Ogawa \\ Institute of Social and Economic Research, \\ Osaka University \\ Hirokuni Uchiyama \\ Graduate School of Economics \\ Osaka University
}

* This research was partially supported by Grants-in-Aid for Scientific Research 12124207 of the Ministry of Education. Any remaining errors are the sole responsibility of the authors. 
An attempt is made to estimate a state space model of investment and borrowing in a Bayesian framework and extract the unobservable agency cost of Japanese firms by firm size. Our estimates of the agency cost exhibited a declining trend in the late $80 \mathrm{~s}$ and then switched to an increasing trend in the $90 \mathrm{~s}$. We pin down the driving force of agency cost to be the market value of land. Furthermore, we find that investment and borrowing behavior of small firms is very much affected by their agency cost in the late $80 \mathrm{~s}$ and the $90 \mathrm{~s}$. Our evidence demonstrates that imperfection of capital market is notable for small firms in Japan.

JEL Classification Number: C51, E22, E44, and E51

Keywords: Agency cost, Investment, Collateral, Land, Borrowing, State space model, Kalman filter, Gibbs sampling

\section{Kazuo Ogawa}

Institute of Social and Economic Research, Osaka University, 6-1 Mihogaoka, Ibaraki, Osaka, 567-0047 JAPAN

Tel: +81- 6- 6879-8570 Fax: +81- 6-6878-2766

E-mail:ogawa@iser.osaka-u.ac.jp

Hirokuni Uchiyama

Graduate School of Economics, Osaka University, 1-7 Machikaneyama, Toyonaka, Osaka, 560-0043 JAPAN

E-mail: uchiyamahirokuni@srv.econ.osaka-u.ac.jp 


\section{Introduction}

In the presence of asymmetric information between lenders and borrowers, financial arrangements arise to prevent borrowers from acting contrary to the interests of lenders. In addition, lenders can monitor the behavior of borrowers to enforce such arrangements. The resulting agency cost caused by this inefficiency drives a wedge between the cost of internal and external funds, known as external finance premium. The agency cost or external finance premium reflects the creditor's cost of collecting the debtor's information and monitoring the debtor's behavior and the cost arising from lemon problem or moral hazard problem. The premium for external funds influences the cost of external funds and thereby affects investment of the debtor.

It is frequently asserted that excessive fluctuations of investment by Japanese firms in the late 1980 s to the 90 s are mainly caused by change in external finance premium of the corresponding period. As is well known, the external finance premium is inversely associated with the borrower's collateralizable net worth. In particular, real estate had played a collateral role in Japan, under the expectation that land prices would never fall. In fact, land price soared in the late $80 \mathrm{~s}$ when investment increased noticeably and as land price plummeted in the 90 s, investment activity became stagnant.

Plausible as this story sounds, it is quite difficult to demonstrate in a rigorous manner that this story was indeed true. The main obstacle in conducting empirical study along this line is unobservability of agency cost facing borrowers. Therefore in the past studies some kind of proxy was used to represent the movement of agency cost. One popular candidate is land asset of firms at market price. There are a number of studies to show a positive correlation of investment with land assets. ${ }^{1}$ However, it may be possible to interpret the land value of firms as future profitability of investment rather than collateral to alleviate the agency cost.

In this study we give more direct evidence for the role of the agency cost in explaining the investment activities of Japanese firms in the late 1980s to 90s. This can be accomplished by estimating the unobservable agency cost directly by estimating the state space model by the Kalman filter in a Bayesian framework to extract the common factors from the observable variables closely related to the agency cost. ${ }^{2}$ As far as the authors know, this is a first attempt to estimate the agency cost the Japanese firms faced in the turmoil period of the late 80 s to the 90 s.

In the course of conducting our research, we take account of the possibility that

\footnotetext{
${ }^{1}$ Foe example, see Ogawa et al. (1996), Suzuki and Ogawa(1997), Ogawa and Suzuki(1998, 2000).

2 Our idea of extracting agency cost stems from Stock and Watson(1991) where an unobservable composite index is extracted from comovement among economic variables.
} 
the firms with different size might face different magnitude of agency cost. It is because there exists institutional device in Japan that helps to narrow the informational asymmetry between lenders and borrowers: industry groups known as keiretsu. Firms within a keiretsu are able to reduce agency costs for several reasons. First, they have close ties with affiliated banks, which hold both debt and equity in the group's firms. This reduces conflicts among investors. Secondly, group firms enjoy long-term, stable relationships with their affiliated banks. Bank employees often hold management positions in the firms. This explains why agency costs were lower for firms within keiretsu groups in comparison to unaffiliated firms. Since large firms tend to be affiliated with banks, we can compare the magnitude of agency cost and its impact on investment activities by using the less aggregated firm data classified by firm size.

Let us preview our findings. We find that the agency cost decreased in the late 80 s when the land price soared, while the agency cost increased substantially in the 90 s when the land price precipitated. This pattern of agency cost is observed irrespective of firm size and industry. Furthermore, we find that investment and borrowing are closely associated with the agency cost, which in turn is affected negatively by the land value of firms. As for the effect of agency cost on investment and borrowings, it is noticeably large for small firms in the 90s. Our results are consistent with the theoretical verdict of the agency cost literature, indicating that investment activities of Japanese firms in the turbulent period of the late 80 s to the 90 s are successfully explained by the changing pattern of agency cost.

The paper is organized as follows. Section 2 briefly reviews the agency cost model of investment and derives the fundamental equations to be estimated. Then the model is cast into state space form. Section 3 explains the econometric procedure to estimate unobservable agency cost. Section 4 describes the data set and shows some descriptive statistics of the variables used in the subsequent analysis. In Section 5 we present estimated series of agency cost and discuss the association of the agency cost with investment, borrowings, land asset and interest rate premium of firms. Concluding remarks are given in Section 6.

\section{Agency Cost Model of Investment and Borrowing}

We construct a model of corporate investment and borrowing with agency cost or external finance premium explicitly taken into consideration. The model consists of four equations: investment equation, borrowing equation, land asset equation, and interest rate spread equation. Agency cost is a key variable of each equation. A brief explanation is made on each equation of the model. 
It is well known that marginal profitability of investment or marginal $\mathrm{q}$ is a sufficient statistics of investment under perfect capital market when a firm incurs an extra convex cost in adjusting investment. ${ }^{3}$ However, once we relax the assumption of perfect capital market and incorporate the asymmetric information between lenders and borrowers into the model, marginal $\mathrm{q}$ is no longer sufficient statistics of investment and the degree of asymmetry or the magnitude of agency cost matters for investment decision. ${ }^{4}$ The upshot is that the factors to affect the agency cost enter the investment function as an additional explanatory variable. For example, cash flow or land as collateral can be a popular candidate besides marginal $\mathrm{q}$ in investment function. Moreover, the manner in which cash flow or land affects investment differs across firms with different agency cost structure. It has been asserted that the structure of agency cost depends on the firms' attributes. For example, Fazzari et al.(1988) shows that the effect of cash flow on investment depends on the age of firm. Hoshi et al.(1991) demonstrates that the impact of cash flow on investment hinges upon whether a firm is a member of industrial group or not. Himmelberg et al. (1999) shows that the ownership of the firm affects the impact of cash flow on investment.

We specify investment equation as a function of marginal $\mathrm{q}$ and unobservable agency cost.

$$
\frac{I_{t}}{K_{t-1}}=\alpha_{1}+\beta_{1} q_{t}+\gamma_{1} A C_{t}+\varepsilon_{1 t}
$$

where $I_{t}$ : real investment in period $t$

$K_{t}$ : capital stock at the end of period $t$

$q_{t}:$ marginal $q$ in period $t$

$A C_{t}:$ agency cost in period $t$

$\varepsilon_{1 t}:$ error term in period $t$.

The agency cost, defined as the difference between the cost of internal finance and external finance, affects the level of borrowing. When the agency cost is low, a firm has more incentive to increase borrowing. Therefore we express the ratio of borrowing to capital stock or borrowing ratio as a function of agency cost as well as marginal q.

$$
\frac{\Delta B_{t}}{p_{t}^{I} K_{t-1}}=\alpha_{2}+\beta_{2} q_{t}+\gamma_{2} A C_{t}+\varepsilon_{2 t}
$$

\footnotetext{
3 See Hayashi(1982).

${ }^{4}$ See Hubbard(1998) for a survey of investment behavior under imperfect capital market.
} 
where $\Delta B_{t}$ : increment of borrowings in period $t$

$$
\begin{aligned}
& p_{t}^{I} K_{t-1}: \text { capital stock at replacement cost at the end of period } t-1 . \\
& \varepsilon_{2 t}: \text { error term in period } t
\end{aligned}
$$

The agency cost is inversely associated with the collateralizable net worth of the firm. In particular land asset had long played a collateral value in Japan under the expectation that land price would never fall. However, close association of borrowing with land asset made loans insolvent once land price plummeted in the 90s.

Therefore we regard land asset as a proxy of collateralizable net worth and express the agency cost as a function of the ratio of land asset to tangible asset (land asset plus capital stock). The following equation is a relationship between the ratio of land stock to tangible asset and the agency cost.

$$
\frac{p_{t}^{L} L_{t-1}}{p_{t}^{I} K_{t-1}+p_{t}^{L} L_{t-1}}=\alpha_{3}+\gamma_{3} A C_{t}+\varepsilon_{3 t}
$$

where $p_{t}^{L} L_{t-1}$ : land stock evaluated at market price at the end of period $t-1$.

$$
\varepsilon_{3 t}: \text { error term in period } t
$$

The interest rate spread between the borrowing interest rate and the risk-free rate directly reflects the magnitude of agency cost, so that the interest rate spread is written as an increasing function of the agency cost.

$$
\operatorname{spread}_{t}=\alpha_{4}+\gamma_{4} A C_{t}+\varepsilon_{4 t}
$$

where spread $_{t}$ : the interest rate spread between the borrowing interest rate and the risk-free rate in period $t$.

$\varepsilon_{4 t}:$ error term in period $t$

Now we have four equations relating the agency cost to investment, borrowings, land asset and interest rate spread. To close the model, we need the equation to describe the movement of agency cost. We assume that the agency cost is generated by a fourth 
order AR process. ${ }^{5}$

$$
\begin{aligned}
& A C_{t}= \phi_{1} A C_{t-1}+\phi_{2} A C_{t-2}+\phi_{3} A C_{t-3}+\phi_{4} A C_{t-4}+v_{t} \\
& \text { where } v_{t}: \text { error term distributed as iid } N(0,1)
\end{aligned}
$$

It is assumed that this transition equation is stationary. ${ }^{6}$

Now we are ready for casting our model into state space form. The state space model consists of measurement equations and transition equation. The measurement equation is defined as an equation in which unobserved variable explains observed variables. In our model measurement equations correspond to eq.(1) to (4). Measurement equation is summarized as follows:

$$
\begin{gathered}
\left(\begin{array}{c}
I_{t} / K_{t-1} \\
\Delta B_{t} / p_{t}^{I} K_{t-1} \\
p_{t}^{L} L_{t-1} /\left(p_{t}^{I} K_{t-1}+p_{t}^{L} L_{t-1}\right) \\
\operatorname{spread}_{t}
\end{array}\right)=\left(\begin{array}{c}
\gamma_{1} \\
\gamma_{2} \\
\gamma_{3} \\
\gamma_{4}
\end{array}\right) A C_{t}+\left(\begin{array}{c}
\beta_{1} \\
\beta_{2} \\
0 \\
0
\end{array}\right) q_{t}+\left(\begin{array}{c}
\varepsilon_{1 t} \\
\varepsilon_{2 t} \\
\varepsilon_{3 t} \\
\varepsilon_{4 t}
\end{array}\right) \\
\text { where } \varepsilon_{i t}: \text { iid } N\left(0, \sigma_{i}^{2}\right)
\end{gathered}
$$

Note that marginal $\mathrm{q}$ is exogenous in our model. The transition equation is the one to describe the movement of unobservable variable. Eq.(5) is the transition equation in our model. Note that the variance of innovation $v_{t}$ in the transition equation is normalized to be unity in order to identify the other parameters and agency cost. In the state space model we estimate an unobservable agency cost as well as the other parameters and the error variances underlying the model. Explanations of statistical tool we use are now in order.

\section{Econometric Procedure to Estimate the State Space Model}

The agency cost in eq.(1) to (5) is an unobserved variable. The main feature of our paper is to estimate this unobservable variable by extracting the common factor from the co-movement of four observable variables: investment rate, borrowing ratio, ratio of land to tangible asset and interest rate spread. This common factor is identified as the estimate of agency cost. To estimate the co-movement, the Kalman filter technique is adopted. It is the algorithm of estimating unobserved variable or state

\footnotetext{
${ }^{5}$ The choice of lag length is partially motivated by the quarterly data set we use.

${ }^{6}$ Agency cost model represented by eqs.(5) and (6) is analyzed by Uchiyama (2002), where selection of lag order and non-stationarity test (structural change test) of eq. (5) is conducted by Bayes factor.
} 
variables from Gaussian linear state space model. ${ }^{7}$

Since relatively small sample is dealt with in this study and we estimate a number of parameters and extract the unobservable series of agency cost from the state space model, the Bayesian approach would be appropriate. In a Bayesian framework the parameters and the agency cost are all treated as unobservable random variables to be inferred from observable data. We use the Gibbs sampler, one of the Markov Chain Monte Carlo (MCMC) simulation techniques to obtain the parameters to characterize the marginal distribution from conditional distribution. ${ }^{8}$

\section{Bayesian Inference via Gibbs Sampler}

In Bayesian inference the estimates such as the means and standard deviations of parameters are derived from their marginal posterior distributions which consist of their prior distributions and sample likelihood as follows.

$$
p(\theta \mid Y)=\frac{p(\theta) L(\theta \mid Y)}{p(Y)}
$$

where $p(\theta \mid Y)$ : posterior density of parameters $\theta$

$Y$ : sampled data

$p(\theta)$ : prior density of $\theta$

$L(\theta \mid Y)$ : likelihood function

$p(Y)$ : marginal density of $Y$

To find the marginal posterior distributions from the given conditional posterior distributions, Gibbs sampler is carried out. The procedure of Gibbs sampler in the state space model is developed by Carter and Kohn (1994). ${ }^{9}$ When their Gibbs sampler is applied to our model, the procedure can be divided into four steps. ${ }^{10}$ In the following steps we denote the $j$-th iteration by superscript $j$.

Step 1. Generate $A C_{t}^{(j)}$ for $t=1,2,3, \cdots, T$.

We derive means, $\overline{A C}_{t}^{(j)}$, and variances, $\Sigma_{A C t}^{(j)}$, of $A C_{t}$ for $t=1,2,3, \cdots, T$ from

\footnotetext{
7 See Hamilton (1994) for the detailed explanations of the algorithm of Kalman filter.

${ }^{8}$ See Casella and George (1992) for the comprehensive survey of the Gibbs sampler

9 They propose the multi-move method of Kalman filter via Gibbs sampler. Their method is efficient and the speed of convergence is faster than the single-move method.

${ }^{10}$ See Carter and Kohn (1994) and Kim and Nelson (1999) for more detailed explanations on this procedure.
} 
Kalman filter using parameters in the (j-1)-th iteration, and generate each $A C_{t}^{(j)}$ from normal distribution with means $\overline{A C}_{t}^{(j)}$ and variances $\Sigma_{A C t}^{(j)}$, i.e.,

$$
\left\{A C_{t}^{(j)} \mid \gamma^{(j-1)}, \quad \beta^{(j-1)}, \quad \sigma^{2(j-1)}, \quad \phi^{(j-1)}\right\} \sim_{N}\left(\overline{A C}_{t}^{(j)}, \Sigma_{A C t}^{(j)}\right)
$$

Step 2. Generate $\gamma^{(j)}$ and $\beta^{(j)}$ in measurement equations.

We generate the coefficients, $\gamma^{(j)}, \beta^{(j)}$, of measurement equations from normal distribution conditional on $A C_{t}$ and other parameters, $\sigma^{2(j-1)}, \phi^{(j-1)}$, i.e.,

$$
\left\{\gamma^{(j)}, \beta^{(j)} \mid \sigma^{2(j-1)}, \phi^{(j-1)}, A C_{t}^{(j)}\right\} \sim_{N}\left(\left(\bar{\gamma}^{(j)}, \bar{\beta}^{(j)}\right), \quad \Sigma_{(\gamma, \beta)}^{(j)}\right)
$$

Step 3. Generate $\phi^{(j)}$ in the transition equation.

We generate the coefficients, $\phi^{(j)}$, of transition equation from the truncated normal distribution conditional on $A C_{t}$ and other parameters, i.e.,

$$
\left\{\phi^{(j)} \mid \sigma^{2(j-1)}, \quad \gamma^{(j)}, \beta^{(j)},, A C_{t}^{(j)}\right\} \sim N\left(\bar{\phi}^{(j)}, \Sigma_{\phi}^{(j)}\right) 1[s(\phi)]
$$

where $1[s(\phi)]$ : indicator function to return unity if the roots of $\phi(L)=0$ lie outside the unit circle, otherwise zero. ${ }^{11}$

Step 4. Generate $\sigma^{2(j)}$ in the measurement equations.

We generate the variances, $\sigma^{2(j)}$, of measurement equations from the inverted gamma distribution conditional on $A C_{t}$ and other parameters, i.e.,

$$
\begin{gathered}
\left\{\sigma^{2(j)} \mid \gamma^{(j)}, \quad \beta^{(j)}, \phi^{(j)}, A C_{t}^{(j)}\right\} \sim I G\left(v, \bar{\sigma}^{2(j)}\right) \\
\text { where } v: \text { posterior degree of freedom. }
\end{gathered}
$$

By iterating these four steps, the conditional distribution of each parameter converges to the invariant marginal distribution independent of the other parameters. The sample extracted from converged distribution shapes the posterior marginal distribution, and the parameter estimators are obtained from this sample. As for the priors, we use noninformative ones for all the parameters but error variances. In this study, the first 1000 iterations of Gibbs sampler is discarded for convergence, and the next 5000 iterations are taken as our sample. A sequence of iterative steps converged after 1000 iterations based on a diagnostic proposed by Geweke (1992). Since the

\footnotetext{
${ }^{11}$ This truncated normal distribution is adopted to guarantee the stationarity of the transition equation.
} 
sample has auto-correlation, the variance formed directly from the sample tends to be overestimated. To reduce the auto-correlation, we re-form the posterior distribution from the means of each 10 successive elements of the original sample with 5000 elements. ${ }^{12}$ Accordingly, 500 sample elements are obtained from this re-formed sample, and we derive the means, standard deviations, medians and the $95 \%$ posterior probability bands $(2.5 \%$-th and $97.5 \%$-th values of the sample) from this new sample.

\section{Comparison across Different Firm Groups}

Since the variance of innovation of the agency cost is normalized as unity in each firm group, comparison of the agency cost across different firm groups is not necessarily rigorous. Therefore, we adopt the following strategy. We compute the extent to which the agency cost affects four observable variables: investment rate, borrowing ratio, ratio of land asset to tangible asset and interest rate spread by multiplying the estimated series of the agency cost by the corresponding coefficient $\left(\gamma_{1}, \gamma_{2}, \gamma_{3}, \gamma_{4}\right)$ of each measurement equation for each firm group. This exercise helps us to see how closely each four observable variable is associated with the agency cost. As for the effect of land asset on the agency cost, we multiply the ratio of land stock to tangible asset, $p_{t}^{L} L_{t-1} /\left(p_{t}^{L} L_{t-1}+p_{t}^{I} K_{t-1}\right)$, by the reciprocal of its coefficient $\left(\gamma_{3}\right)$ in eq. (3).

\section{Data Construction and Descriptive Analysis}

We use quarterly data reported in the Quarterly Report of Financial Statements of Incorporated Business (QRFS) of the Ministry of Finance. The QRFS produces quarterly reports for manufacturing and non-manufacturing firms on major items from their balance sheets and profit and loss statements, disaggregated by firm size. The virtue of this data source is the decomposition of tangible fixed assets into components and we can construct a time series of land stock, which plays an important role in our analysis. Our sample period includes the first quarter of 1975 through to the first quarter of 1998, covering the long booms and the severe recessions in the 1980s and the 90s.

We measure firm size by capital. Firms are categorized into three groups by their level of equity capital: small, medium, and large firms. Small firms have under $¥ 100$ million yen in capital, medium firms have between $¥ 100$ and $¥ 1000$ million yen in capital, and large firms have over $¥ 1000$ million yen in capital.

${ }^{12}$ It is referred to as batch mean. 


\section{Data Construction}

The discontinuity of the time series is one major problem of the QRFS. This arises from a complete renewal of the corporations in the sample every April, after which the sample is fixed for one year. It is necessary to adjust for this discontinuity in a consistent manner. Fortunately, the survey contains the values of main balance sheet items at the beginning and end of each period covered in the sample. This implies that we can compute the time series of flow variables in a consistent manner. Once the flow series is computed, the perpetual inventory method can be applied to construct the stock series. See Ogawa(2000b) for the detailed procedures for constructing the consistent data series.

\section{Descriptive Analysis of Major Variables in the Firm's Balance Sheet}

Let us first describe the characteristics of major variables used in our analysis. Table 1 to 4 shows the sample means of investment rate, rate of change in total borrowing, rate of change in land stock at market price and marginal q, respectively, over the whole sample period as well as three subperiods. They are the second quarter of 1975 to the fourth quarter of 1986, the first quarter of 1987 to the first quarter of 1991, and the second quarter of 1991 to the first quarter of 1998. The second subperiod corresponds to the long booms (Heisei Keiki) in the late 80s when the land price exhibited an upward trend. In the third subperiod the land price plummeted, plunging the Japanese economy into stagnancy.

The sample average of the gross investment rate, given in Table 1, is highest in the second subperiod and lowest in the third subperiod for manufacturing as well as non-manufacturing industries. The volatility of fixed investment is highest among small firms for both manufacturing and non-manufacturing industries.

The average rate of change in total borrowing, given in Table 2, is highest in the second subperiod except for large firms in manufacturing industries. It is highest for small firms of non-manufacturing industries. The average rate of change amounts to $4 \%$ per quarter or $16 \%$ per annum. By contrast the average rate of change is negative for large firms in manufacturing industries except for the third subperiod. This might reflect a shift of financing from bank loans to equity or bond for large manufacturing firms.

Table 3 gives the sample average of the rate of change in land stock at market price. There is no discernible difference across firm groups. The reason is as follows. The change in land stock is decomposed into two factors: increment or decrement of land stock in real terms and change in land price common to all firms. Close movements 
of the change in land stock across firm size hints that the latter component dominates. The average rate of change in land stock is highest in the second subperiod and lowest in the third subperiod.

Finally Table 4 gives the sample average of marginal $q$. Marginal $\mathrm{q}$ is constructed by estimating a VAR model of profit rate and discount rate, as is originally developed by Abel and Blanchard (1986). ${ }^{13}$ It should be noted that marginal q of small firms is much larger than that of medium or large firms.

\section{Estimates of Agency Cost and Their Association with Firms' Activities}

Four measurement equations relating the agency cost to investment, borrowing, land asset and interest rate spread, along with transition equation of the agency cost, are estimated in a Bayesian context by Kalman filter technique for three firm groups (small, medium and large firms) of manufacturing as well as non-manufacturing industries. Overall the estimation results support the theoretical supposition that agency cost is important especially for small firms that are likely to be constrained in capital market. ${ }^{14}$

The response of investment to agency cost is negative and significant in the sense that the $95 \%$ band does not include zero, irrespective of firm size and industry. The smaller the firms are, the larger the mean response of investment to agency cost is in absolute value. In other words, investment of small firms is more sensitive to agency cost. The response of borrowings to agency cost is also negative and significant except for large firms of manufacturing industries. The response of borrowing is larger in absolute value for smaller firms, which implies that borrowings of small firms are much more affected by agency cost. The collateral role of land in alleviating agency cost, measured by the reciprocal of $\gamma_{3}$, is also successfully estimated irrespective of firm size and industry. An increase of land value at market value reduces the agency cost. The effect of agency cost on interest rate spread is positive and significant except for small firms in non-manufacturing industries. The interest rate of large firms seems to reflect the agency cost quite accurately.

As for the effect of marginal q on investment, it is significantly positive except for large firms in non-manufacturing industries. The marginal $\mathrm{q}$ has significantly positive effect on borrowing only for medium firms in manufacturing industries and large firms in non-manufacturing industries. Insignificance of marginal $\mathrm{q}$ variable in borrowing equation of small firms is consistent with the importance of agency cost rather than the fundamental profitability for small firms.

${ }^{13}$ See Ogawa(2000a) for detailed procedure to construct marginal q series.

${ }^{14}$ Details of the estimation results are given in Appendix Tables. 


\section{Estimates of Agency Cost}

Figure 1 and 2 show the estimates of agency cost from the first quarter of 1976 to the first quarter of 1998 for manufacturing and non-manufacturing industries, respectively. The agency cost is normalized at 100 in the first quarter of 1976. What is common to all firms is an increasing trend of agency cost in the 90s when land price plummeted. We also observe a declining trend of agency cost in the late 80 s for small and medium firms in manufacturing industries and small and large firms in non-manufacturing industries. Note that land price soared noticeably in the late $80 \mathrm{~s}$. The agency cost started to fall at the beginning of the 80 s for large firms in manufacturing industries. Development of financial markets starting from the 80 s lowered agency cost and thus enabled large manufacturing firms to finance from a variety of sources cheaply, leading to fall of agency cost.

\section{Association of Agency Cost with Firms' Activities}

We turn to the relationship of agency cost with firms' attributes and activities such as investment, borrowing, land asset, and interest rate spread. It can be seen by the product of agency cost with the corresponding parameters. ${ }^{15}$

The effect of agency cost on investment is shown in Figure 3. It is seen that increase of agency cost in the 90s depressed investment to a large extent. Note that the effect is especially large for small firms. We also observe that fall of agency cost in the late $80 \mathrm{~s}$ is associated with vigorous investment. The effect is notably large for small firms in non-manufacturing industries. The effect of agency cost on borrowing is shown in Figure 4. It is clear that rise of agency cost in the 90s drastically reduced borrowing of small firms. Conversely fall of agency cost in the late 80 s led to an increase of borrowing of small firms. It should be noted that borrowing of large firms are unaffected by the agency cost. Figure 5 shows the association of interest rate spread with agency cost. We see that the interest rate spread of large firms is most affected by the agency cost. In the 80 s the interest rate spread tends to decline due to fall of agency cost, while the interest rate spread exhibits an increasing trend in the $90 \mathrm{~s}$, reflecting a rise of agency cost. Lastly Figure 6 shows the association of agency cost with land asset. We see that agency cost is closely related to the value of land asset. In the late $80 \mathrm{~s}$ the soaring land price contributed to reducing agency cost, while the agency cost rose

\footnotetext{
15 The computed values in the subsequent figures are normalized by subtracting the computed value at the first quarter of 1976 from the values in the subsequent period. Therefore, the computed values are normalized to zero at the first quarter of 1976.
} 
sharply in the 90s when the land price plummeted.

\section{Concluding Remarks}

In this study we made an attempt to estimate a state space model of investment and borrowing in a Bayesian framework and extract the unobservable agency cost of Japanese firms by firm size. Our approach seems to be quite successful since we can explain the investment and borrowing behavior of firms in the late $80 \mathrm{~s}$ and $90 \mathrm{~s}$ by the movement of agency cost. We find that the agency cost exhibited a declining trend in the late $80 \mathrm{~s}$ and an increasing trend in the $90 \mathrm{~s}$ irrespective of firm size. We can pin down the driving force of agency cost to be the market value of land. Furthermore, we find that investment and borrowing behavior of small firms is very much affected by their agency cost in the late 80s and 90s. In particular our results can shed light on the cause of stagnancy of business activities of small firms in the $90 \mathrm{~s}$. In the 90 s land price plummeted and collateral value of land fell drastically, which in turn affected severely investment and borrowing of small firms by raising their agency cost. Our evidence demonstrates that imperfection of capital market is notable for small firms in Japan. 


\section{Reference}

Abel, A. B. and O.J. Blanchard(1986)." The Present Value of Profits and Cyclical Moments in Investment, " Econometrica 54, 249-273.

Carter, C.K. and P. Kohn(1994)." On Gibbs Sampling for State Space Models," Biometrica 81, 541-553.

Casella, G. and E.I. George(1992). “Explaining the Gibbs Sampler,” The American Stastician 46, 167-174.

Fazzari, S. M., Hubbard., R. G., and B.C. Petersen(1988). “ Financing Constraints and Corporate Investment," Brookings Pap. Econ. Act. 1, 141-195.

Geweke, J. (1992). "Evaluating the accuracy of sampling-based approaches to the calculation of posterior moments," in J.M.Bernardo, J.O.Berger, A.P.Dawid and A.F.M.Smith (eds.) Bayesian Statistics 4, Oxford University Press, Oxford.

Hamilton, J.(1994). Time Series Analysis, Princeton University Press.

Hayahi, F. (1982). “ Tobin's Marginal q and Average q: A Neoclassical Inrerpretation, “Econometrica 50, 1, 213-224.

Himmelberg, C.P., Hubbard, R.G. and D. Palia(1999)." Understanding the Determination of Managerial Ownership and the Link between Ownership and Performance, “ J. Finan. Econ. 53, 353-384.

Hoshi, T., Kashyap, A. and D. Scharfstein(1991)." Corporate Structure, Liquidity and Investment: Evidence from Japanese Industrial Groups, "Quart. J. Econ. 106, 33-60.

Hubbard, R.G.(1998). “ Capital-Market Imperfections and Investment.” J. Econ. Lit. 36, 193-225.

Kim, C.J. and C.R. Nelson(1999). State-Space Models with Regime Switching, MIT press, Cambridge. 
Ogawa, K.(2000a).” Kin'yu Seisaku no Hakyu Keiro: Kigyo Kibo Betsu Deta ni Motoduku Jisshou Bunseki [Monetary Transmission Mechanism: An Empirical Analysis Based on Japanese Firm Data Classified by Firm Size]," in Osano, H. and Y. Honda (eds.) Gendai no Kinyu to Seisaku, Nihon Hyoronsha, pp.74-110.

Ogawa, K. (2000b)." Monetary Policy, Credit and Real Activity: Evidence from the Balance Sheet of Japanese Firms, " Journal of Japanese and International Economies 14, 385-407.

Ogawa, K., Kitasaka, S.,Yamaoka, H. and Y. Iwata(1996).” Borrowing Constraints and the Role of Land Asset in Japanese Corporate Investment Decision," Journal of the Japanese and International Economies 10, pp.122-149.

Ogawa, K. and K. Suzuki(1998).” Land Value and Corporate Investment: Evidence from Japanese Panel Data," Journal of Japanese and International Economies 12, 232-249.

Ogawa, K. and K. Suzuki(2000).” Demand for Bank Loans under Borrowing Constraints: A Panel Study Japanese Firm Data," Journal of the Japanese and International Economies 14, 2000, 1-21.

Stock, J.H. and M.W. Watson(1991)." A Probability Model of the Coincident Economic Indicators," in K. Lahiri and G.H. Moore (eds.) Leading Economic Indicators: New Approaches and Forecasting Records, 63-89, Cambridge University Press.

Suzuki, K. and K. Ogawa(1997).” Tochi Kakaku no Hendo to Setsubi Toshi Nippon no Seizougyou ni kansuru Paneru Deta niyoru Bunseki - (Fluctuation in Land Prices and Capital Investment - Evidence from Panel data of Japanese Manufacturing Firms -," The Economic Review (The Institute of Economic Research, Hitotsubashi University), 48, 218-226.

Uchiyama, H. (2002). "The Index of Aggregate Agency Cost and Heisei Boom," mimeographed. 
Table 1

Descriptive Statistics of Fixed Investment Rate by Firm Size

\begin{tabular}{|l|ccc|c|}
\hline & $75: 2-86: 4$ & $87: 1-91: 1$ & $91: 2-98: 1$ & $75: 2-98: 1$ \\
& & & & \\
\hline $\begin{array}{l}\text { Manufacturing } \\
\text { Small firms }\end{array}$ & 4.10 & 4.47 & 2.69 & \\
Medium firms & 3.72 & 4.03 & 2.69 & 3.74 \\
Large firms & 3.58 & 3.90 & 3.00 & $(0.98)$ \\
& & & 3.47 \\
Non-manufacturing & & & $(0.74)$ \\
Industries & & & 3.46 \\
Small firms & 4.19 & 5.40 & 3.19 & $(0.63)$ \\
Medium firms & 4.24 & 4.38 & 3.29 & $(0.99)$ \\
Large firms & 4.02 & 4.78 & 3.77 & $(0.69)$ \\
& & & & 4.09 \\
\end{tabular}

Notes: The values in parentheses are standard deviation.

Table 2

Descriptive Statistics of the Rate of Change in Total Borrowing by Firm Size

\begin{tabular}{|l|ccc|c|}
\hline & $75: 2-86: 4$ & $87: 1-91: 1$ & $91: 2-98: 1$ & $75: 2-98: 1$ \\
\hline $\begin{array}{l}\text { Manufacturing } \\
\text { Industries } \\
\text { Small firms }\end{array}$ & 1.23 & 2.27 & 0.31 & \\
Medium firms & 0.42 & 1.19 & 0.26 & 1.14 \\
& & & & $(1.37)$ \\
Large firms & -0.23 & -0.58 & 0.07 & 0.51 \\
& & & & $-0.91)$ \\
Non-manufacturing & & & & $(1.39)$ \\
Industries & & & \\
Small firms & 1.92 & 4.02 & 0.49 & 1.87 \\
Medium firms & 1.49 & 2.75 & 0.33 & $(1.61)$ \\
Large firms & 0.89 & 2.77 & -0.15 & $(1.39)$ \\
& & & & 0.92 \\
\hline
\end{tabular}

Notes: The values in parentheses are standard deviation. 
Table 3

Descriptive Statistics of the Rate of Change in Land Stock at Market Price by Firm Size

$(\%)$

\begin{tabular}{|c|c|c|c|c|}
\hline & $75: 2-86: 4$ & $87: 1-91: 1$ & $91: 2-98: 1$ & $75: 2-98: 1$ \\
\hline \multicolumn{5}{|l|}{$\begin{array}{l}\text { Manufacturing } \\
\text { Industries }\end{array}$} \\
\hline Small firms & 1.14 & 4.56 & -2.45 & $\begin{array}{c}0.68 \\
(2.97)\end{array}$ \\
\hline Medium firms & 0.97 & 4.12 & -2.50 & $\begin{array}{c}0.52 \\
(2.85)\end{array}$ \\
\hline Large firms & 1.05 & 4.22 & -2.47 & $\begin{array}{r}0.56 \\
(2.86) \\
\end{array}$ \\
\hline \multicolumn{5}{|c|}{$\begin{array}{l}\text { Non-manufacturing } \\
\text { Industries }\end{array}$} \\
\hline Small firms & 1.23 & 4.67 & -2.14 & $\begin{array}{r}0.84 \\
(2.89)\end{array}$ \\
\hline Medium firms & 1.03 & 4.40 & -2.29 & $\begin{array}{c}0.64 \\
(2.86)\end{array}$ \\
\hline Large firms & 1.03 & 4.44 & -2.10 & $\begin{array}{c}0.71 \\
(2.81)\end{array}$ \\
\hline
\end{tabular}

Notes: The values in parentheses are standard deviation.

Table 4

Descriptive Statistics of Marginal $q$ by Firm Size

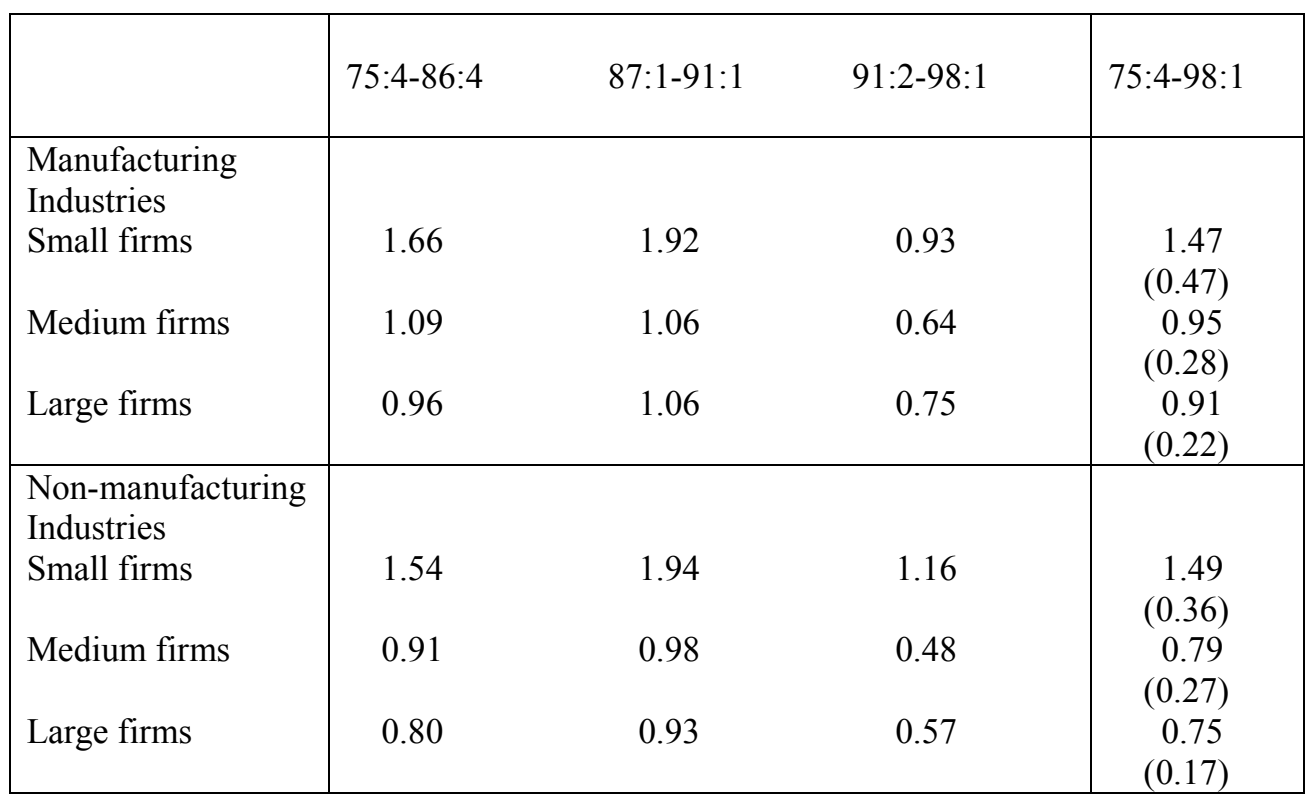

Notes: The values in parentheses are standard deviation. 
Figure 1. Agency Cost of Manufacturing Industries $\quad(1976$ Q1 = 100$)$

\section{(a) Small Firms}

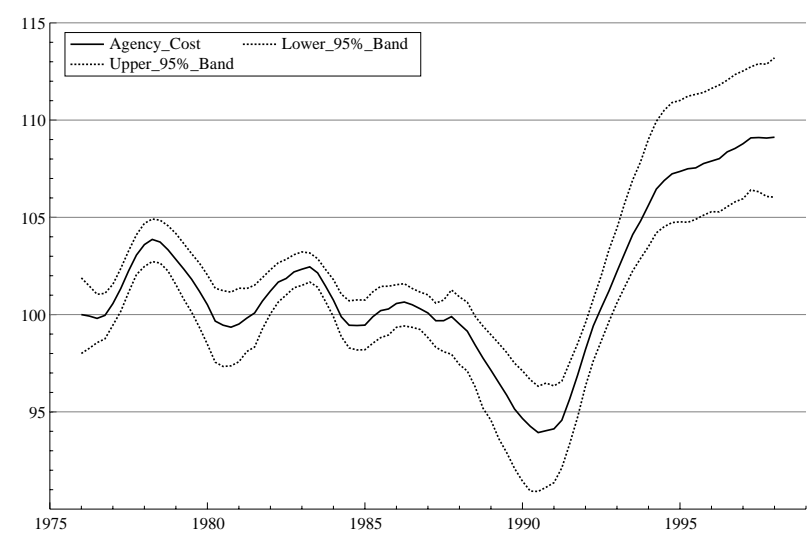

(b) Medium Firms

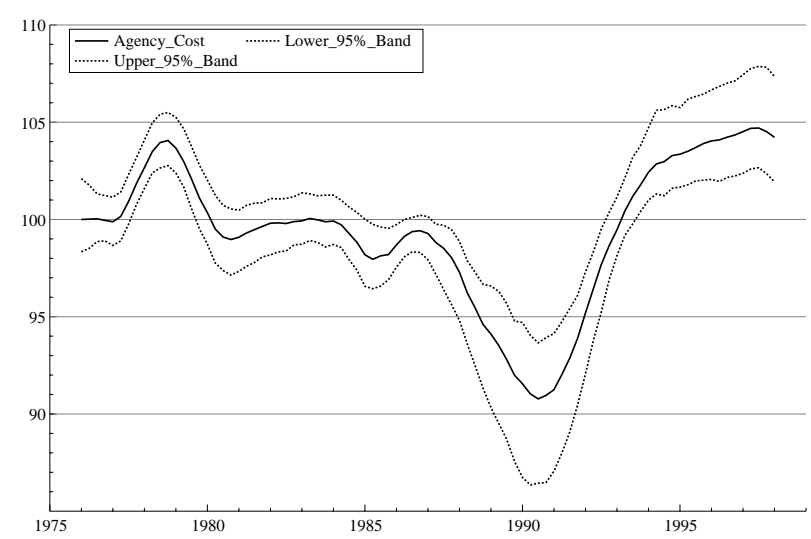

(c) Large Firms

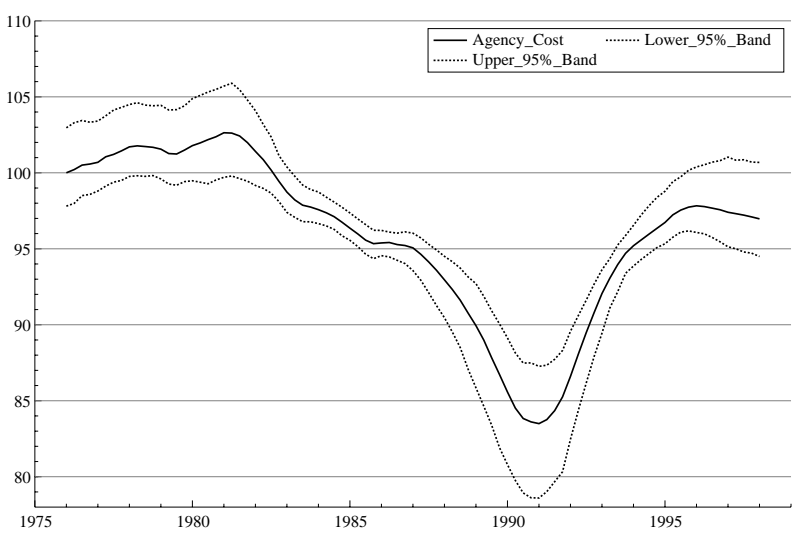


Figure 2. Agency Cost of Non-Manufacturing Industries $\quad(1976$ Q1 = 100 )

(a) Small Firms

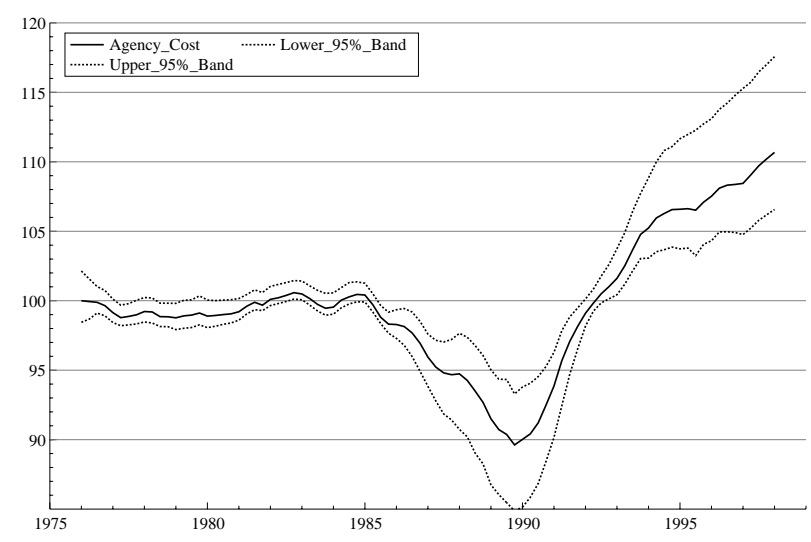

(b) Medium Firms

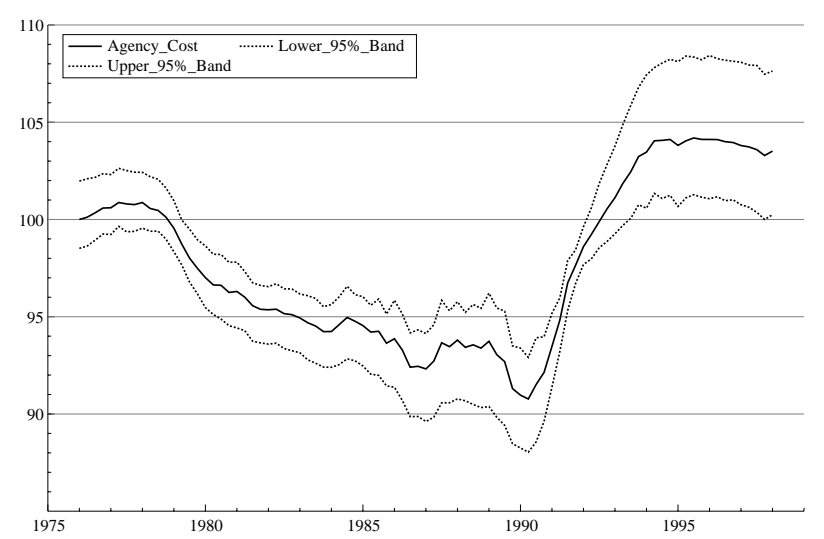

(c) Large Firms

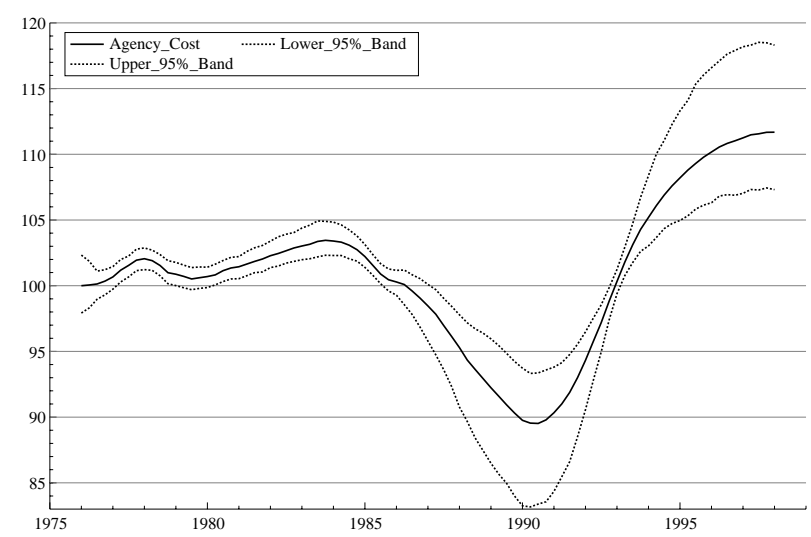




\section{Figure 3. Effect of Agency cost on Investment Rate}

$$
\text { ( } 1976 \text { Q1 = } 0 \text { ) }
$$

(a) Manufacturing Industries

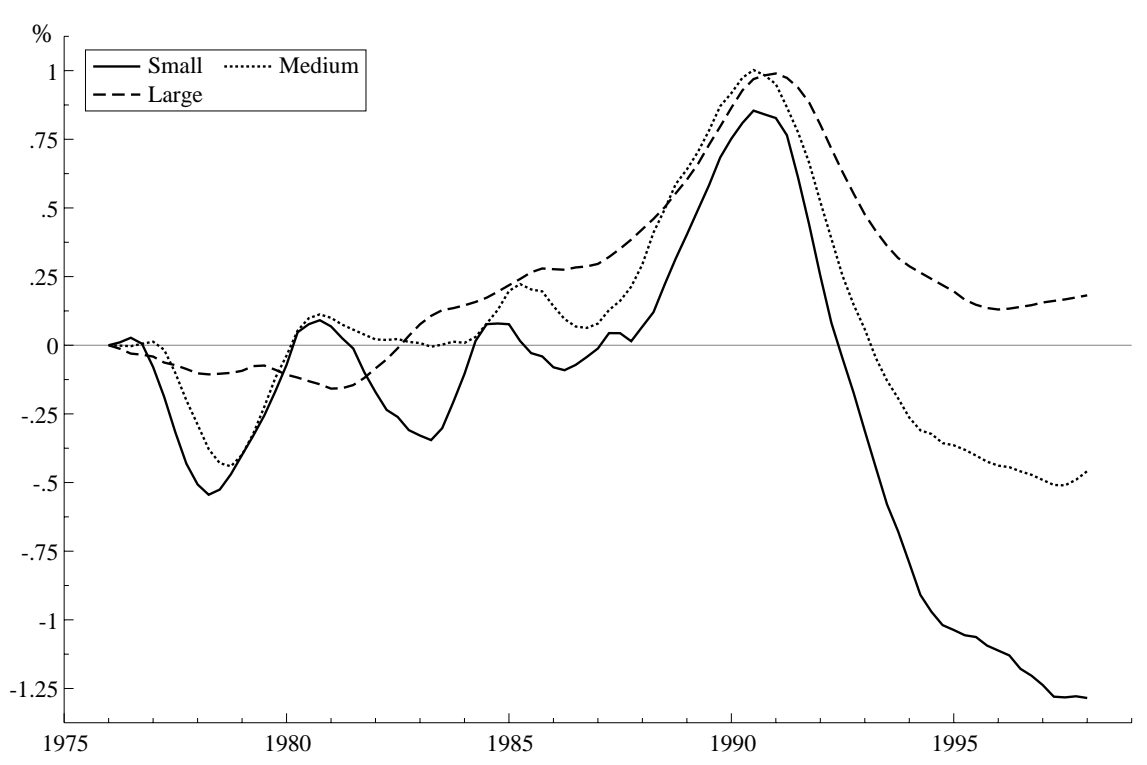

(b) Non-Manufacturing Industries

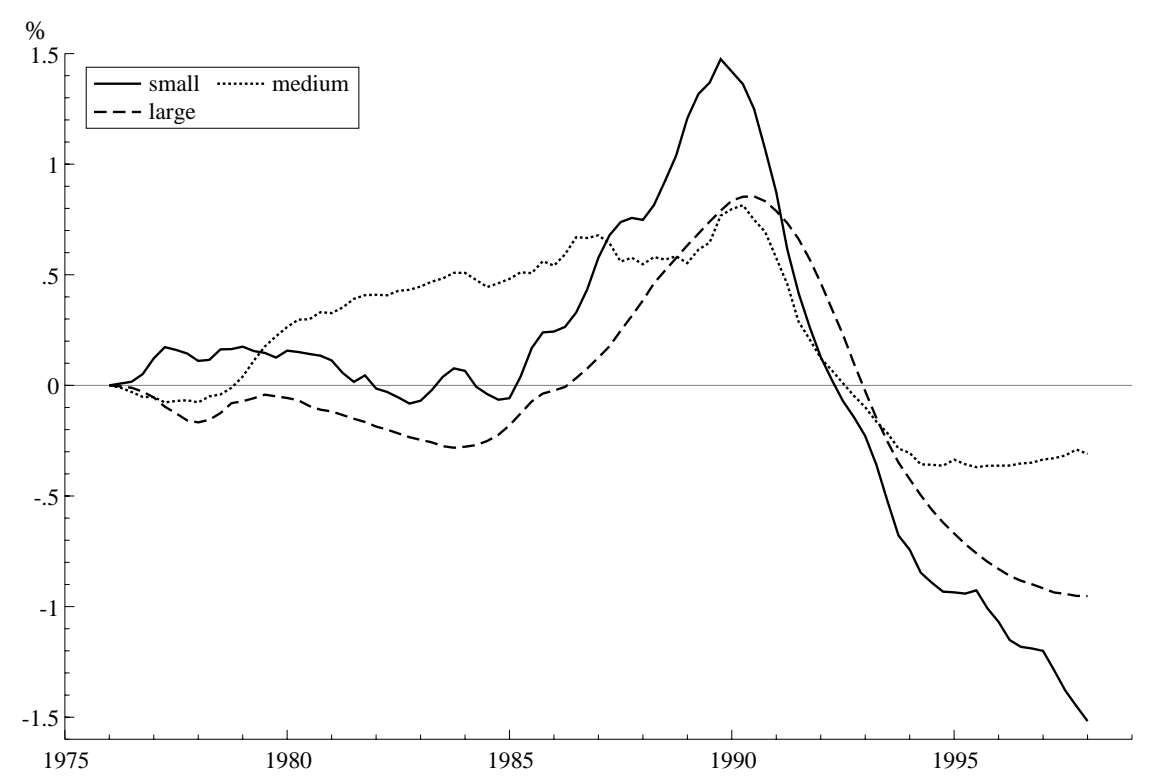


Figure 4. Effect of Agency cost on Borrowing Ratio

$$
(1976 \text { Q1 = } 0)
$$

(a) Manufacturing Industries

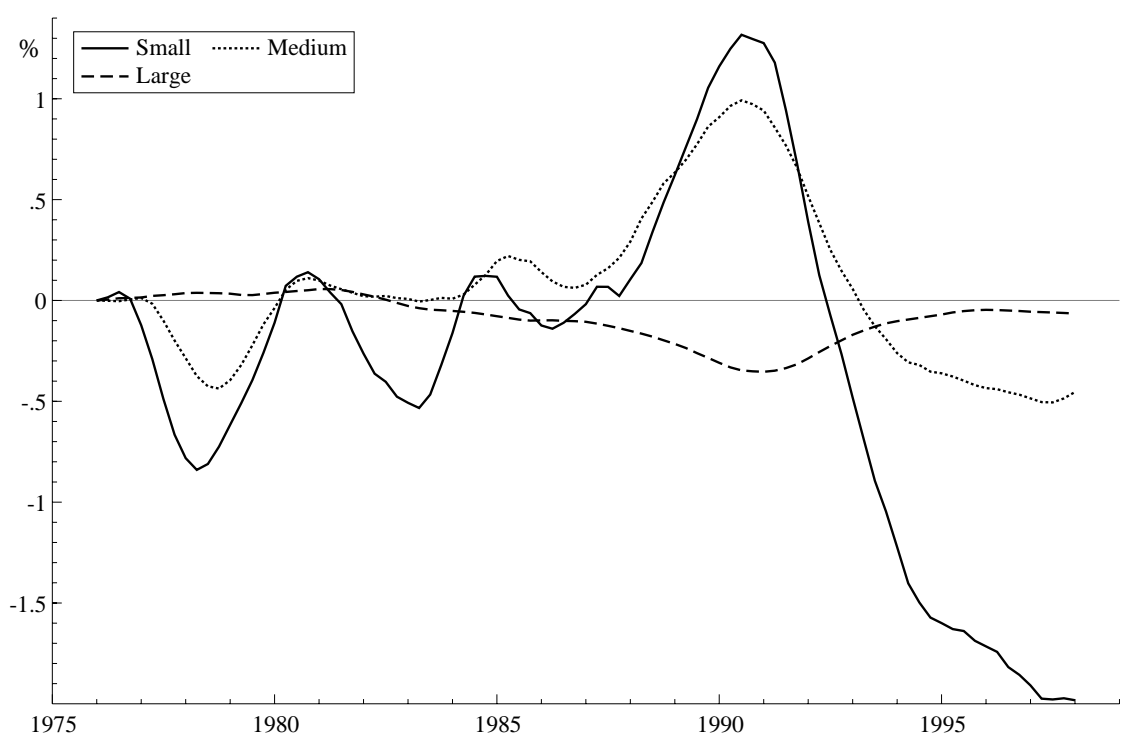

(b) Non-Manufacturing Industries

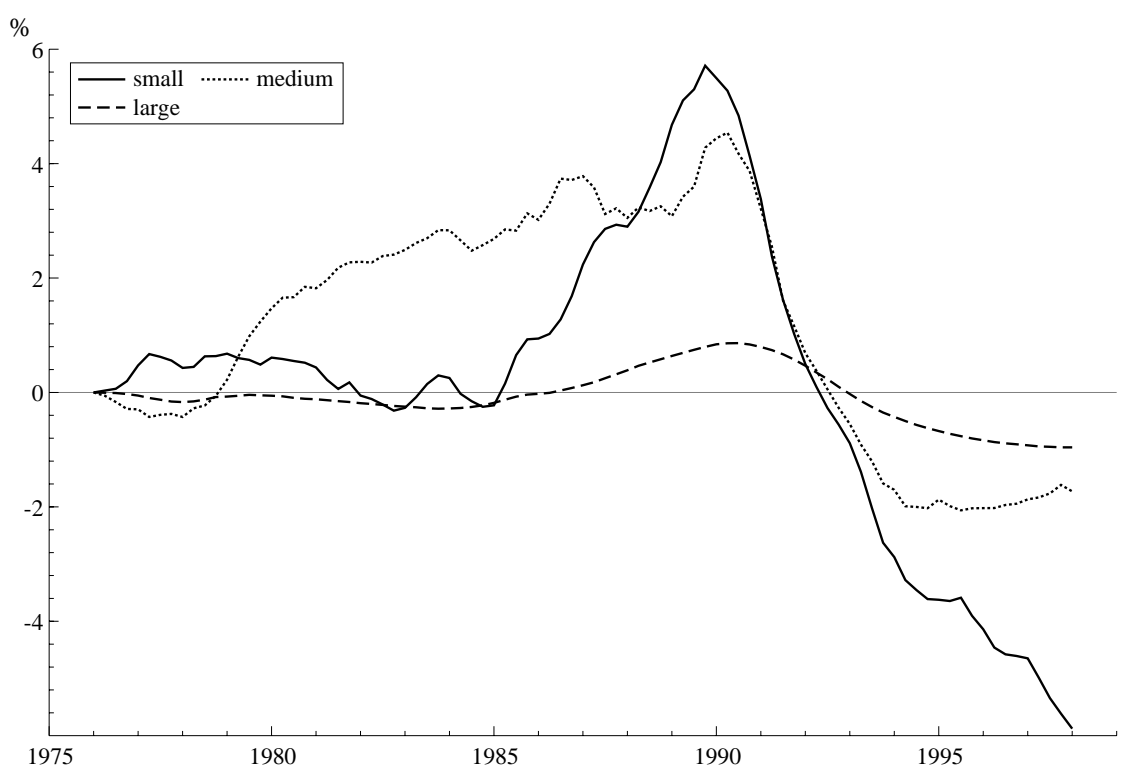




\section{Figure 5. Effect of Agency cost on Interest Rate Spread}

$$
\text { ( } 1976 \text { Q1 = } 0 \text { ) }
$$

(a) Manufacturing Industries

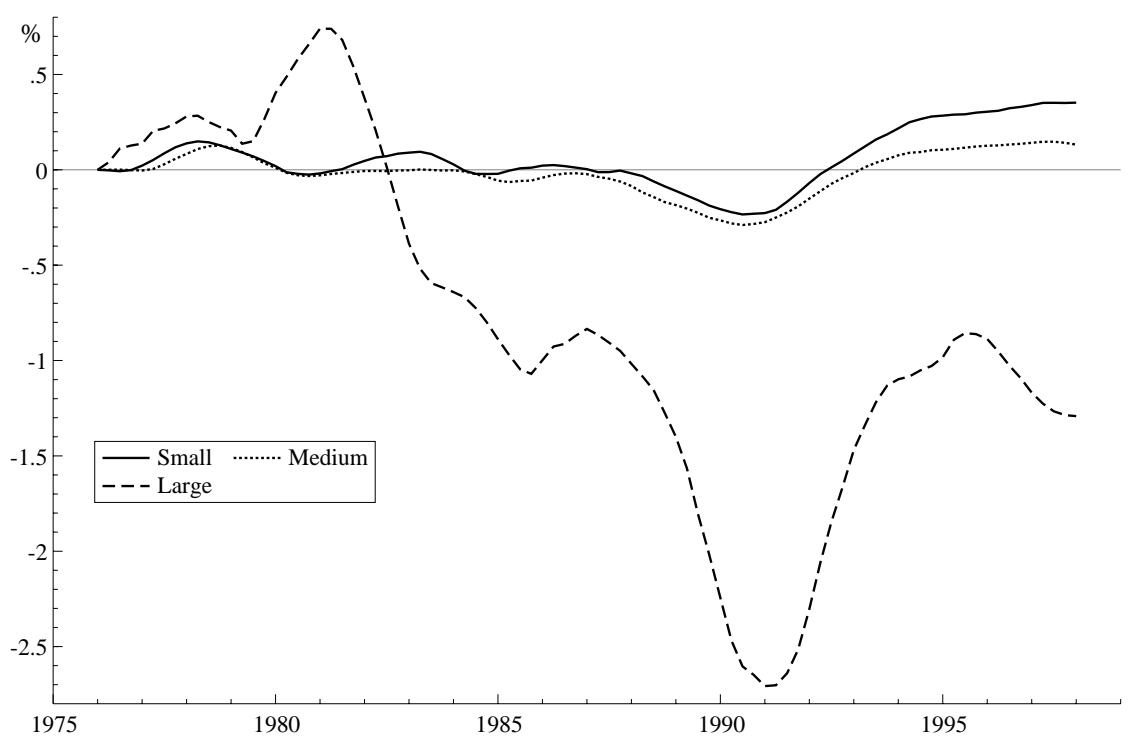

(b) Non-Manufacturing Industries

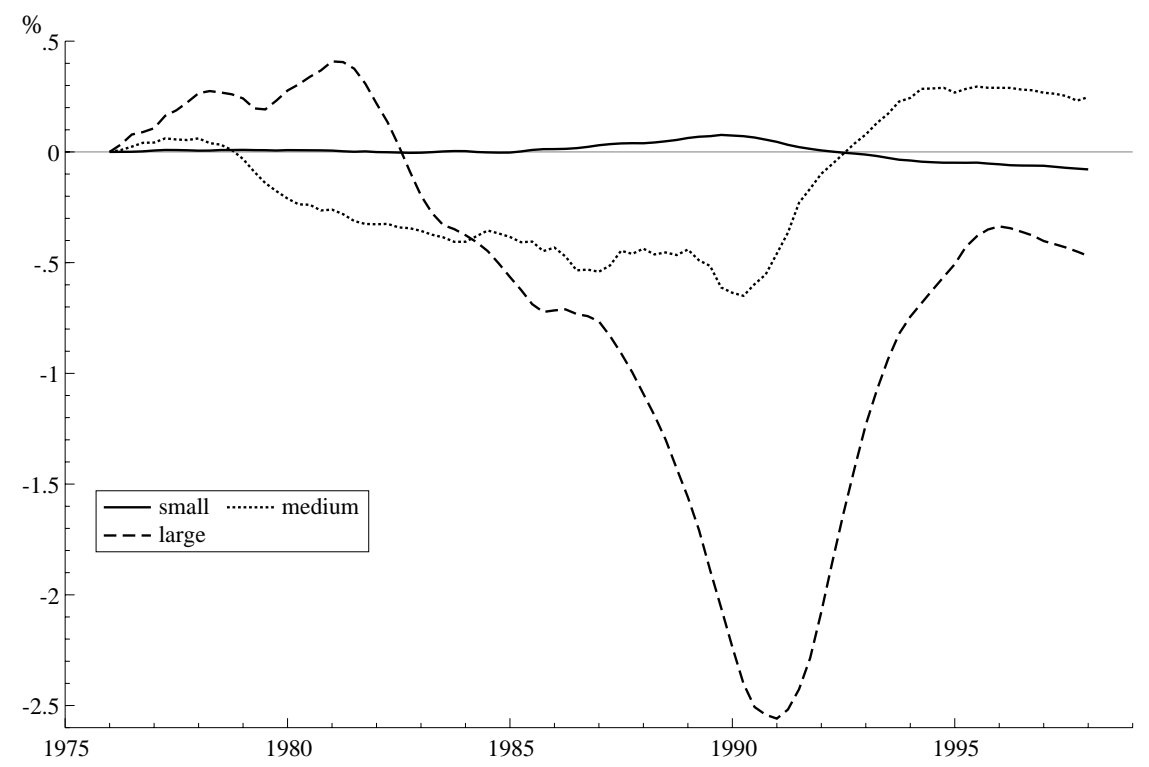


Figure 6. Effect of Ratio of Land Asset to Tangible Asset on Agency cost ( 1976 Q1 = 0 )

(a) Manufacturing Industries

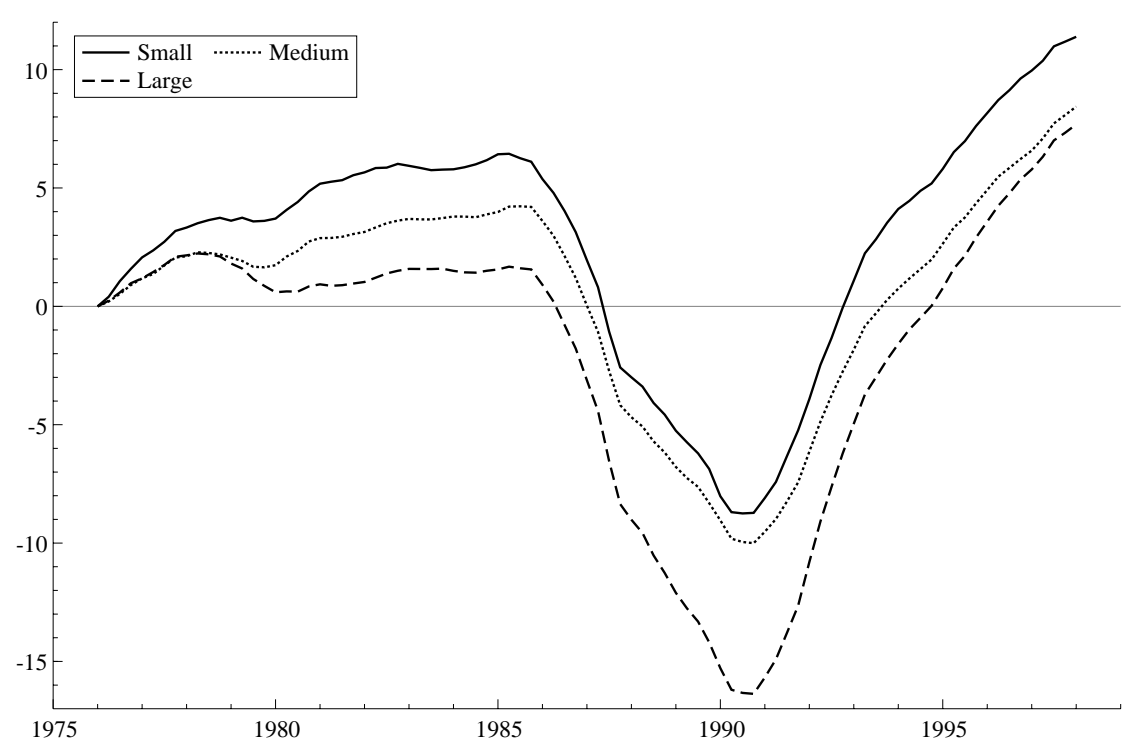

(b) Non-Manufacturing Industries

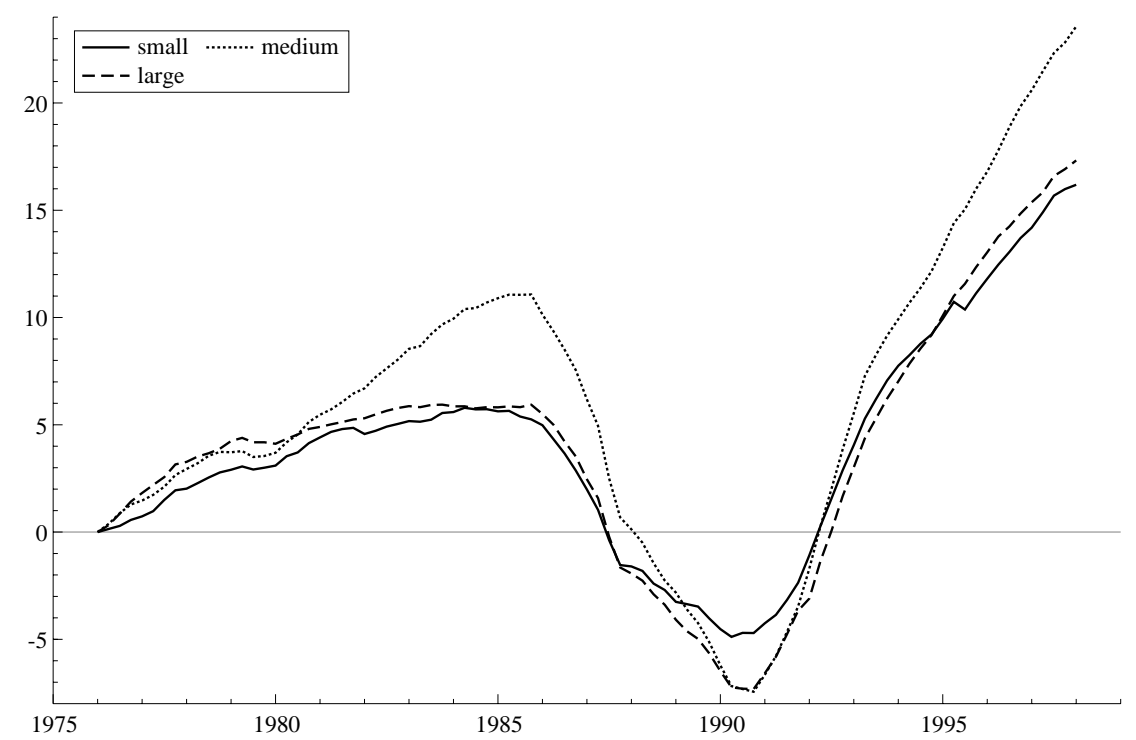




\section{Appendix Tables}

Bayesian Prior and Posterior Distribution:

Agency Cost Model of Investment and Borrowing

Table A-1. Manufacturing Small Firms ${ }^{a}$

\begin{tabular}{c|cc|cccccc}
\hline & Prior & & \multicolumn{5}{|c}{ Posterior } & Distribution \\
Parameters $^{b}$ & mean & S.D. $^{c}$ & mean & S.D. $^{c}$ & median & $95 \%$ bands $^{d}$ & CD $^{e}$ \\
\hline$\phi_{1}$ & 0 & 1 & 1.066 & 0.081 & 1.068 & $(0.893$ & $1.226)$ & 0.006 \\
$\phi_{2}$ & 0 & 1 & 0.023 & 0.074 & 0.025 & $(-0.143$ & $0.162)$ & 0.001 \\
$\phi_{3}$ & 0 & 1 & -0.001 & 0.068 & 0.001 & $(-0.134$ & $0.138)$ & -0.014 \\
$\phi_{4}$ & 0 & 1 & -0.133 & 0.053 & -0.136 & $(-0.224$ & $-0.030)$ & 0.013 \\
$\gamma_{1}$ & 0 & 1 & -0.141 & 0.028 & -0.140 & $(-0.202$ & $-0.090)$ & -0.072 \\
$\gamma_{2}$ & 0 & 1 & -0.217 & 0.046 & -0.216 & $(-0.317$ & $-0.141)$ & -0.015 \\
$\gamma_{3}$ & 0 & 1 & -1.008 & 0.215 & -0.984 & $(-1.475$ & $-0.621)$ & -0.073 \\
$\gamma_{4}$ & 0 & 1 & 0.039 & 0.013 & 0.037 & $(0.018$ & $0.068)$ & 0.034 \\
$\beta_{1}$ & 0 & 1 & 0.983 & 0.176 & 1.005 & $(0.589$ & $1.281)$ & 0.016 \\
$\beta_{2}$ & 0 & 1 & 0.366 & 0.280 & 0.397 & $(-0.224$ & $0.823)$ & 0.051 \\
$\sigma_{1}^{2}$ & 2 & 4 & 0.206 & 0.020 & 0.205 & $(0.170$ & $0.248)$ & -0.009 \\
$\sigma_{2}^{2}$ & 2 & 4 & 1.290 & 0.096 & 1.287 & $(1.103$ & $1.494)$ & 0.032 \\
$\sigma_{3}^{2}$ & 60 & 20 & 19.897 & 1.940 & 20.049 & $(15.82$ & $23.83)$ & -0.014 \\
$\sigma_{4}^{2}$ & 2 & 4 & 0.339 & 0.018 & 0.339 & $(0.303$ & $0.376)$ & -0.026 \\
\hline
\end{tabular}

Note $^{a}$ The first 1000 iterations of Gibbs sampler are discarded to guarantee convergence and the next 5000 iterations are taken as our sample. As butch mean, an average of each 10 successive draws of the original sample is regarded as one sample of target posterior distribution.

${ }^{b}$ See eqs. (5) and (6) for the notations of parameters.

${ }^{c}$ S.D. refers to standard deviation.

${ }^{d} 95 \%$ bands refers to $95 \%$ posterior probability bands.

${ }^{e}$ The convergence diagnostic (CD) statistics is derived from the $i$-th draw of a parameter $\theta^{(i)}$ in the recorded 5000 draws. The statistics is defined as $C D=\frac{\theta_{A}^{-}-\theta_{B}^{-}}{\sqrt{\sigma_{A}^{2} / n_{A}+\sigma_{B}^{2} / n_{B}}}$, where $\overline{\theta_{A}}=$ $\frac{1}{n_{A}} \sum_{i=1}^{n_{A}} \theta^{(i)}, \overline{\theta_{B}}=\frac{1}{n_{B}} \sum_{i=5001-n_{B}}^{5000} \theta^{(i)}$, and $\sqrt{\sigma_{A}^{2} / n_{A}}, \sqrt{\sigma_{B}^{2} / n_{B}}$ are standard deviation of $\overline{\theta_{A}}, \overline{\theta_{B}}$. Here we set $n_{A}=1000$ and $n_{B}=2500$. CD of converged posterior distribution must be asymptotically standard normal distribution. (See Geweke (1992). ) 
Table A-2 . Manufacturing Medium Firms

\begin{tabular}{|c|c|c|c|c|c|c|c|c|}
\hline parameter & $\begin{array}{l}\text { Prior } \\
\text { mean }\end{array}$ & S.D. & mean & $\begin{array}{c}\text { Posterior } \\
\text { S.D. }\end{array}$ & $\begin{array}{c}\text { Distribution } \\
\text { median }\end{array}$ & $95 \%$ bands & & $\mathrm{CD}$ \\
\hline$\phi_{1}$ & 0 & 1 & 1.063 & 0.075 & 1.068 & ( 0.889 & 1.195 ) & -0.067 \\
\hline$\phi_{2}$ & 0 & 1 & 0.026 & 0.075 & 0.030 & $(-0.120$ & 0.163 ) & 0.015 \\
\hline$\phi_{3}$ & 0 & 1 & -0.011 & 0.071 & -0.012 & $(-0.148$ & 0.126 ) & -0.013 \\
\hline$\phi_{4}$ & 0 & 1 & -0.138 & 0.049 & -0.140 & $(-0.240$ & $-0.039)$ & 0.045 \\
\hline$\gamma_{1}$ & 0 & 1 & -0.109 & 0.027 & -0.106 & $(-0.169$ & $-0.059)$ & -0.217 \\
\hline$\gamma_{2}$ & 0 & 1 & -0.108 & 0.031 & -0.104 & $(-0.184$ & $-0.055)$ & -0.197 \\
\hline$\gamma_{3}$ & 0 & 1 & -1.117 & 0.195 & -1.114 & $(-1.535$ & $-0.748)$ & -0.157 \\
\hline$\gamma_{4}$ & 0 & 1 & 0.031 & 0.011 & 0.030 & ( 0.013 & 0.056 ) & 0.092 \\
\hline$\beta_{1}$ & 0 & 1 & 1.704 & 0.159 & 1.720 & ( 1.294 & 1.952 ) & -0.093 \\
\hline$\beta_{2}$ & 0 & 1 & 0.642 & 0.175 & 0.662 & ( 0.196 & 0.918 ) & -0.117 \\
\hline$\sigma_{1}^{2}$ & 2 & 4 & 0.181 & 0.017 & 0.181 & ( 0.151 & 0.215 ) & -0.078 \\
\hline$\sigma_{2}^{2}$ & 2 & 4 & 0.417 & 0.036 & 0.420 & ( 0.348 & 0.489 ) & -0.103 \\
\hline$\sigma_{3}^{2}$ & 60 & 20 & 19.018 & 2.579 & 18.900 & ( 14.83 & 24.13 ) & 0.110 \\
\hline$\sigma_{4}^{2}$ & 2 & 4 & 0.256 & 0.014 & 0.256 & $(0.230$ & 0.283 ) & 0.051 \\
\hline
\end{tabular}

Note: See the note of Table A-1. 
Table A-3 . Manufacturing Large Firms

\begin{tabular}{|c|c|c|c|c|c|c|c|c|}
\hline parameter & $\begin{array}{l}\text { Prior } \\
\text { mean }\end{array}$ & S.D. & mean & $\begin{array}{c}\text { Posterior } \\
\text { S.D. }\end{array}$ & $\begin{array}{c}\text { Distribution } \\
\text { median }\end{array}$ & $95 \%$ bands & & $\mathrm{CD}$ \\
\hline$\phi_{1}$ & 0 & 1 & 1.085 & 0.071 & 1.087 & ( 0.936 & 1.217 ) & 0.076 \\
\hline$\phi_{2}$ & 0 & 1 & 0.028 & 0.076 & 0.029 & $(-0.117$ & 0.177 ) & -0.049 \\
\hline$\phi_{3}$ & 0 & 1 & 0.007 & 0.072 & 0.010 & $(-0.137$ & 0.145 ) & -0.011 \\
\hline$\phi_{4}$ & 0 & 1 & -0.157 & 0.051 & -0.157 & $(-0.255$ & $-0.059)$ & 0.019 \\
\hline$\gamma_{1}$ & 0 & 1 & -0.060 & 0.014 & -0.059 & $(-0.088$ & $-0.038)$ & 0.109 \\
\hline$\gamma_{2}$ & 0 & 1 & 0.021 & 0.009 & 0.021 & $(0.002$ & 0.041 ) & -0.004 \\
\hline$\gamma_{3}$ & 0 & 1 & -0.918 & 0.175 & -0.908 & $(-1.290$ & $-0.608)$ & 0.108 \\
\hline$\gamma_{4}$ & 0 & 1 & 0.155 & 0.032 & 0.153 & ( 0.097 & 0.223 ) & -0.101 \\
\hline$\beta_{1}$ & 0 & 1 & 1.093 & 0.098 & 1.099 & ( 0.893 & $1.275)$ & 0.024 \\
\hline$\beta_{2}$ & 0 & 1 & -0.229 & 0.118 & -0.234 & $(-0.462$ & $0.020)$ & -0.012 \\
\hline$\sigma_{1}^{2}$ & 2 & 4 & 0.306 & 0.027 & 0.309 & $(0.247$ & $0.353)$ & -0.025 \\
\hline$\sigma_{2}^{2}$ & 2 & 4 & 0.694 & 0.034 & 0.693 & ( 0.630 & $0.761)$ & 0.0415 \\
\hline$\sigma_{3}^{2}$ & 60 & 20 & 19.449 & 2.695 & 19.720 & ( 14.41 & $24.27)$ & 0.0137 \\
\hline$\sigma_{4}^{2}$ & 2 & 4 & 0.258 & 0.071 & 0.237 & ( 0.167 & 0.432 ) & -0.001 \\
\hline
\end{tabular}

Note: See the note of Table A-1. 
Table A-4 . Non-Manufacturing Small Firms

\begin{tabular}{|c|c|c|c|c|c|c|c|c|}
\hline parameter & $\begin{array}{l}\text { Prior } \\
\text { mean }\end{array}$ & S.D. & mean & $\begin{array}{c}\text { Posterior } \\
\text { S.D. }\end{array}$ & $\begin{array}{l}\text { Distribution } \\
\text { median }\end{array}$ & $95 \%$ bands & & $\mathrm{CD}$ \\
\hline$\phi_{1}$ & 0 & 1 & 1.092 & 0.092 & 1.098 & ( 0.871 & $1.248)$ & 0.136 \\
\hline$\phi_{2}$ & 0 & 1 & 0.009 & 0.076 & 0.009 & $(-0.142$ & 0.162 ) & 0.028 \\
\hline$\phi_{3}$ & 0 & 1 & -0.014 & 0.074 & -0.014 & $(-0.154$ & 0.135 ) & -0.038 \\
\hline$\phi_{4}$ & 0 & 1 & -0.114 & 0.071 & -0.119 & $(-0.259$ & 0.027 ) & -0.116 \\
\hline$\gamma_{1}$ & 0 & 1 & -0.142 & 0.034 & -0.141 & $(-0.217$ & $-0.080)$ & 0.279 \\
\hline$\gamma_{2}$ & 0 & 1 & -0.550 & 0.143 & -0.542 & $(-0.864$ & $-0.301)$ & 0.283 \\
\hline$\gamma_{3}$ & 0 & 1 & -0.948 & 0.230 & -0.935 & $(-1.451$ & $-0.554)$ & 0.262 \\
\hline$\gamma_{4}$ & 0 & 1 & -0.007 & 0.006 & -0.007 & $(-0.020$ & 0.004 ) & 0.037 \\
\hline$\beta_{1}$ & 0 & 1 & 0.786 & 0.130 & 0.788 & ( 0.539 & 1.046 ) & -0.030 \\
\hline$\beta_{2}$ & 0 & 1 & 0.156 & 0.316 & 0.178 & $(-0.495$ & $0.756)$ & -0.033 \\
\hline$\sigma_{1}^{2}$ & 2 & 4 & 0.247 & 0.015 & 0.247 & $(0.218$ & 0.277 ) & 0.025 \\
\hline$\sigma_{2}^{2}$ & 2 & 4 & 3.201 & 0.253 & 3.208 & ( 2.706 & 3.712 ) & 0.071 \\
\hline$\sigma_{3}^{2}$ & 60 & 20 & 14.47 & 0.83 & 14.48 & ( 12.88 & $16.19)$ & -0.075 \\
\hline$\sigma_{4}^{2}$ & 2 & 4 & 0.413 & 0.021 & 0.411 & $(0.373$ & 0.458 ) & -0.031 \\
\hline
\end{tabular}

Note: See the note of Table A-1. 
Table A-5 . Non-Manufacturing Medium Firms

\begin{tabular}{|c|c|c|c|c|c|c|c|c|}
\hline parameter & $\begin{array}{l}\text { Prior } \\
\text { mean }\end{array}$ & S.D. & mean & $\begin{array}{c}\text { Posterior } \\
\text { S.D. }\end{array}$ & $\begin{array}{c}\text { Distribution } \\
\text { median }\end{array}$ & $95 \%$ bands & & $\mathrm{CD}$ \\
\hline$\phi_{1}$ & 0 & 1 & 0.980 & 0.120 & 0.994 & $(0.705$ & $1.181)$ & -0.064 \\
\hline$\phi_{2}$ & 0 & 1 & 0.076 & 0.091 & 0.072 & $(-0.091$ & 0.282 ) & 0.026 \\
\hline$\phi_{3}$ & 0 & 1 & -0.020 & 0.076 & -0.019 & $(-0.178$ & $0.125)$ & -0.001 \\
\hline$\phi_{4}$ & 0 & 1 & -0.075 & 0.071 & -0.078 & $(-0.203$ & 0.084 ) & 0.035 \\
\hline$\gamma_{1}$ & 0 & 1 & -0.088 & 0.020 & -0.086 & $(-0.134$ & $-0.055)$ & -0.146 \\
\hline$\gamma_{2}$ & 0 & 1 & -0.492 & 0.114 & -0.470 & $(-0.758$ & $-0.310)$ & -0.160 \\
\hline$\gamma_{3}$ & 0 & 1 & -0.731 & 0.172 & -0.713 & $(-1.120$ & $-0.436)$ & -0.115 \\
\hline$\gamma_{4}$ & 0 & 1 & 0.070 & 0.024 & 0.066 & ( 0.036 & 0.123 ) & 0.053 \\
\hline$\beta_{1}$ & 0 & 1 & 1.049 & 0.180 & 1.038 & ( 0.710 & 1.429 ) & -0.045 \\
\hline$\beta_{2}$ & 0 & 1 & 0.069 & 0.735 & 0.017 & $(-1.201$ & 1.599 ) & -0.045 \\
\hline$\sigma_{1}^{2}$ & 2 & 4 & 0.220 & 0.012 & 0.220 & ( 0.196 & 0.245 ) & 0.043 \\
\hline$\sigma_{2}^{2}$ & 2 & 4 & 1.089 & 0.111 & 1.084 & ( 0.875 & 1.335 ) & 0.043 \\
\hline$\sigma_{3}^{2}$ & 60 & 20 & 27.430 & 1.852 & 27.232 & ( 24.07 & 31.58 ) & -0.0087 \\
\hline$\sigma_{4}^{2}$ & 2 & 4 & 0.352 & 0.026 & 0.353 & ( 0.298 & 0.400 ) & 0.007 \\
\hline
\end{tabular}

Note: See the note of Table A-1. 
Table A-6 . Non-Manufacturing Large Firms

\begin{tabular}{|c|c|c|c|c|c|c|c|c|}
\hline parameter & $\begin{array}{l}\text { Prior } \\
\text { mean }\end{array}$ & S.D. & mean & $\begin{array}{c}\text { Posterior } \\
\text { S.D. }\end{array}$ & $\begin{array}{l}\text { Distribution } \\
\text { median }\end{array}$ & $95 \%$ bands & & $\mathrm{CD}$ \\
\hline$\phi_{1}$ & 0 & 1 & 1.118 & 0.075 & 1.122 & ( 0.961 & $1.260)$ & -0.063 \\
\hline$\phi_{2}$ & 0 & 1 & 0.033 & 0.073 & 0.035 & $(-0.117$ & 0.172 ) & 0.028 \\
\hline$\phi_{3}$ & 0 & 1 & 0.014 & 0.070 & 0.018 & $(-0.123$ & $0.155)$ & -0.015 \\
\hline$\phi_{4}$ & 0 & 1 & -0.194 & 0.057 & -0.196 & $(-0.302$ & $-0.077)$ & 0.041 \\
\hline$\gamma_{1}$ & 0 & 1 & -0.082 & 0.017 & -0.081 & $(-0.123$ & $-0.049)$ & -0.111 \\
\hline$\gamma_{2}$ & 0 & 1 & -0.082 & 0.019 & -0.081 & $(-0.124$ & $-0.048)$ & -0.091 \\
\hline$\gamma_{3}$ & 0 & 1 & -0.976 & 0.217 & -0.962 & $(-1.487$ & $-0.586)$ & -0.083 \\
\hline$\gamma_{4}$ & 0 & 1 & 0.078 & 0.021 & 0.076 & $(0.042$ & $0.122)$ & 0.085 \\
\hline$\beta_{1}$ & 0 & 1 & 0.357 & 0.219 & 0.361 & $(-0.089$ & 0.747 ) & -0.032 \\
\hline$\beta_{2}$ & 0 & 1 & 2.734 & 0.373 & 2.720 & ( 1.946 & 3.456 ) & -0.036 \\
\hline$\sigma_{1}^{2}$ & 2 & 4 & 0.177 & 0.011 & 0.177 & ( 0.156 & 0.199 ) & 0.010 \\
\hline$\sigma_{2}^{2}$ & 2 & 4 & 1.130 & 0.066 & 1.127 & ( 1.013 & $1.271)$ & 0.007 \\
\hline$\sigma_{3}^{2}$ & 60 & 20 & 13.467 & 0.763 & 13.466 & ( 12.03 & 15.03 ) & 0.004 \\
\hline$\sigma_{4}^{2}$ & 2 & 4 & 0.432 & 0.028 & 0.430 & $(0.381$ & 0.491 ) & -0.062 \\
\hline
\end{tabular}

Note: See the note of Table A-1. 